\title{
INVESTIGATION ON SPOT BOOKING AND DYNAMIC OCEAN FREIGHT MODELLING FOR HIGHER SPACE UTILISATION ON ULTRA LARGE CONTAINER VESSELS
}

UDC 629.045

Preliminary communication

\begin{abstract}
Summary
The article deals with the very topical issues of the use of spot ship's space booking and the dynamic adjustment of ocean freight, according to the demand and availability of cargo space on container ships. Container lines are facing the challenges of filling the growing container ships, which also raises the difficulty of managing the overbooking. Two research hypothesis; that $(\mathrm{H} 1)$ freight forwarders have concerns about a new spot booking mode and a dynamic way of formulating ocean rates; and that (H2) freight forwarders feel threatened by Container Lines (CL) to some extent to phase them out from the organization of intermodal transport chains due to the introduction of larger ships and the risk of low space occupation, are followed by the research. A survey between freight forwarders and NVOCCs (Non-Vessel Operating Common Carrier) on a global scale provides guidelines for the further development of CL model for the booking process and the formation of ocean rates because the results expose how new ways of working have a greater impact on the operational and commercial work between CL, freight forwarders and NVOCCs. According to the obtained result, the article proposes a three-step approach to be developed by CL that would bring freight forwarders and NVOCCs closer to a new way of working, reduce business risks, and, as a result, provide leverage to achieve ship space optimization and lower space pressure on container terminals. The study provides new understandings in building new operational models for efficient maritime logistics and brings novelty to the scientific community by defining descriptive gaps in changing strategic and operational approach for ship's cargo space optimization.
\end{abstract}

Key words: $\quad$ maritime transport; shipping; booking; loading optimization; cargo space utilization

\section{Introduction}

The maritime industry is facing rapid changes that have a significant impact on the shipping business and the performance of different stakeholders. Economic conditions, directions of trade, prices of raw materials and energy products, as well as concepts of supply chains are changing. The economic situation in international and domestic markets 
significantly impacts the demand for maritime transport [1]. Carriers seek to mitigate price pressures and rising operating costs resulting from cleaner motor fuels and rising oil prices in global markets by using larger container ships and reducing sailing speeds [2]. They tie into alliances or continue acquisitions to make it easier to fill the space on ULCV (Ultra Large Container Vessels) and reduce the operational cost per container or TEU [3, 4, 5]. Connections also allow them to combine direct services between loading and discharging ports that are usually more acceptable to cargo owners [6] and to send ships faster to scrap, allowing the elimination of older and smaller ships, which are more prone to breakdowns and result in higher maintenance costs [7].

With such decisions, Container Lines (CL) influence the accessibility of shipping space and, consequently, the rise in ocean transport rates [8]. Stopford [9] points out that ocean rates are a mechanism in shipping companies' hands for balancing supply and demand. In 2017, demand growth was $6.4 \%$, while supply increased by only $3.8 \%$, which is also connected to scrap the policy. Thus, shipping companies have recorded better business results in the last two years. Drewery [10] reports that the shipping container industry closed 2017 with USD 7 billion in profits. Ocean rates have also increased, with an average increase of more than $20 \%$ on key Asia-European Union and Asia-USA shipping routes 11]. Nevertheless, rates are far below the level of decades ago, as they currently represent only $50 \%$ of the value at that time. Nielsen et al. [12] point out that container shipping costs fluctuate cyclically, even at oneweek intervals, which Munim and Schramm [13] point out as an extremely short period for operational and commercial adaption of carriers.

CLs are looking for new ways to optimize cargo space. In addition to using different approaches and information tools to optimize cargo space occupancy [14], alliancing, where the ten largest container carriers already control $70 \%$ of the entire container fleet, enables the combination of different services. Moreover, they are considering the introduction of a different booking method and method for setting ocean rates. Ting and Tzeng [15] and Wang et al. [16] state that the ship's space allocation approach and cargo overbooking management can be revenue-oriented, with orientation on price or cost. Dynamic ocean rate formulation, as introduced by Maersk Spot based on timed booking and charging for cancellation or shifting the booking to next sailings, is based on a more recent revenue management (RM) approach and sets new requirements for cargo owners (CO) and freight forwarders (FF) or NVOCCs (Non-Vessel Operating Common Carriers). Wang and Fung [17] point out that such an RM approach has long been useful in air passenger transport, but it cannot be directly used in the container industry because of its specificity. In aviation, freight rates fluctuate greatly over shorter time intervals and adapt dynamically to demand cargo space or seat bookings $[17,18]$. Vinod and Narayan [19] propose an approach that allows higher revenues to be achieved through dynamic price adjustment.

CLs are facing an operational challenge of filling ULCV at the time of booking, which may be up to 6 weeks before the scheduled E.T.D (Expected Time of Departure) and lasts up to a maximum of $48 \mathrm{hrs}$ before ships depart. The main problem is overbooking, as many containers are overbooked or canceled before the ship arrives [20]. CLs can use commercial approaches based on adjusting ocean rates for certain PODs (Port of Discharge), special conditions in POL (Port of Loading), and POD, such as demurrage free time, THC (Terminal Handling Charge) included in ocean freight, etc. Zurheide and Fischer [21] propose an approach whereby carriers favor higher-rate bookings and reject them where the ocean rate does not cover the carriers' operating costs. In the last decade, CLs have primarily formulated their rates based on projected quantities of containers per shipper or consignee or by type of goods, thus agreeing on long-term rates [22]. Such arrangements have enabled shippers or consignees to achieve lower prices over a longer period [23]. 
The change in the way of managing ocean rates and the process of bookkeeping of shipping space can dramatically change the way FFs work. Blanco et al. [1] find in their research that changes in maritime rates do not affect the volume of maritime traffic, so it can be argued that cargo is only moved between different shipping companies or modes of shipping. A survey was conducted between NVOCCs and traditional FFs in the global market to understand the view and approach of FFs on the new way of commercial and operational work with container shipping. Two research hypothesis are raised:

- (H1) FFs have concerns about a new spot booking mode and a dynamic way of formulating ocean rates, which enables optimization of the loading space of a container ship, and

- (H2) FFs feel threatened by CL to a certain extent, with new approaches to phase them out from the organization of intermodal transport chains, as new technological solutions based on the use of on-line tools and one-stop-shop points are adapted for their direct B2B (Business-to-Business) or B2C (Business-to-Customer) approach.

The study provides new understandings and the basis for the shipping and logistics sector in building new operational models for efficient maritime logistics and supply chains. The study brings novelty to the scientific community by defining descriptive gaps in changing strategic and operational decisions of intermodal chains organization as the basis for the development of new models, algorithms, and IT tools by future researches.

\section{Research methodology}

The research addresses new approaches that global CLs have introduced in the booking process, where they provide special rate offers and guarantee container loading on a defined ship to prevent overbooking. A new way of dynamically forming ocean rates based on prebooking and occupancy of the loading space [24] brings opportunities, challenges, and commercial risks to the business of NVOCCs and traditional FFs. Two basic approaches of dynamic rate formulation are possible that supersede the traditional method of setting the ocean freight rates where the same price value is valid for a longer period of time (Fig. 1):

- Strategy for loading space limitations: CLs offer a lower ocean rate for bookings 4 to 5 weeks before a ship's arrival, and then when the ship is becoming full (approx. 2 weeks before the arrival of the ship), the prices are increased (according to the survey the CLs predict a $10 \%$ higher price);

- Strategy for excessive loading slots: CLs offer a lower ocean freight 4-5 weeks before a ship's E.T.A. but in case of excessive slots available in the last days before the arrival of the ship, it may also drop below the level of the rates offered for bookings 4-5 weeks before the ship arrives in an attempt to fill the ship.

The dynamic formulation of ocean rates also includes penalties if a FF makes a booking 3-4 weeks in advance to secure space and a lower ocean rate but postpones the booking to the next ship or cancels it. It is an ongoing practice that the CL charges for booking postponements or cancellations to prevent overbooking, where FFs do not have orders from COs or COs decide to postpone loading due to their commercial reasons.

Thus, the purpose of the research between global NVOCCs and FFs is to get their perspectives on a modified way of managing cargo space on container ships and ocean rates and their adaption to a new way of working in maritime logistics. The survey questionnaire bases on the theoretical starting points and practical foundations of existing cooperation between CLs and NVOCCs or FFs. The survey does not cover COs, who certainly play an important role in the bookkeeping and final acceptance of offered ocean prices. Of course, this is a different stakeholder group, as van den Berg and de Langen [25] note, they have a different view of the importance of the quality of the shipping service, and, consequently, of 
the carrier's ranking in the final selection of the shipping service. Besides, FFs have a deeper insight into the scope and mode of operation when CLs change commercial and operational business conditions.

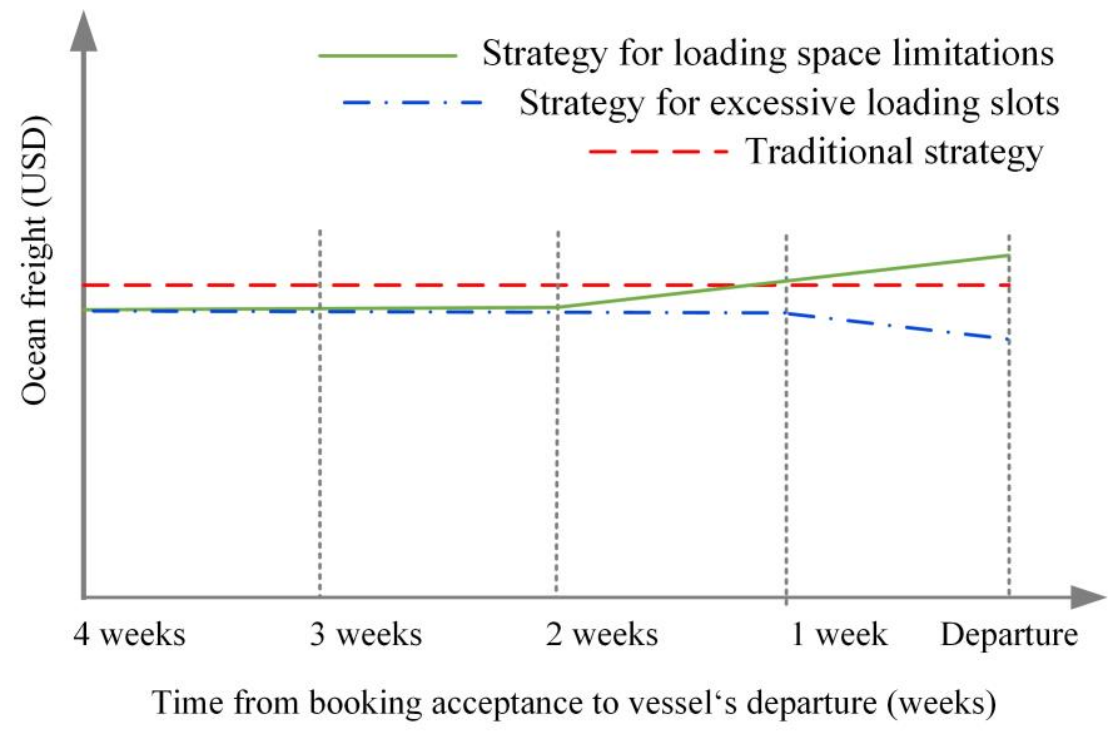

Fig. 1 Dynamic change of ocean rate according to the time of booking and slot availability

Particular emphasis is placed on the narrowly defined commercial-operational maritime logistics tasks that directly impinge on the FF's work in booking the space and ensuring the best possible buying conditions. Among the pre-booking and booking factors of successful shipping, Kannan et al. [26] rank service flexibility and the possibility of shifting bookings, the cost of shipping, and the level of communication with FFs.

The questions and comprehensibility of the sets of questions (Appendix 1) were previously tested following an interview with a European freight forwarding company with head-quarter in Europe, which had already dealt with a new spot booking approach and dynamic ocean rate formulation. The questionnaire is divided into five sections. The first includes basic information about the company's headquarters, the number of employees, the annual volume of container traffic, whether they work as NVOCCs or as a traditional FF (without their Bill of lading - BL), and the most important markets for their commercial operation. The second set contains questions about whether they can negotiate with CLs for long-term prices per each customer or type of goods (NAC - Named Account terms) and whether they are experiencing a new dynamic formulation of ocean rates. FFs are also asked if they approve the modified way of spotting ocean rates.

The third set consists of a set of questions related to understanding the new way of working, the utility of shipping web-based e-portals, the need for further clarification of pricing methodology, and how they respond to any additional costs of raising the level of rates or the cost of moving a booking or even canceling it. NVOCCs and FFs are also asked if they take the risk of overbooking, even if they do not have orders from a CO confirmed, and whether they perceive that the new way may reduce their role in connecting COs with shipping companies. The latter is highlighted by Noteboom and Merckx [27], as CLs are increasingly interested in taking on the role of integrated transport organizer and, consequently, in part, the work of the FF. The same is also confirmed in the study by van den Berg and de Langen [25], where they place the carrier's orientation on door-to-door transport services at the forefront.

The fourth part of the questionnaire inquires whether FFs expect higher operating costs, the impact on the amount of their margin and whether the changed way of booking and 
formulating ocean rates affects the shipping company's choice. The last set checks whether FFs and NVOCCs would be willing to use a special e-platform where different CLs would in one place give spot conditions for booking a container in a given week of departure of the ship by individual POL and what price they would be prepared to pay for such a service in the form of a monthly membership fee.

In total, 400 NVOCCs and FFs globally were invited by e-mail and through the LinkedIn platform to participate in the study. The survey was conducted electronically with the opensource application for web surveys (1ka.si) between July and September 2019. Altogether 90 companies from 23 countries in Asia (18\%), Europe (67\%), North and South America (12\%), and Africa (3\%) responded to the survey. The survey was partially completed by 75 companies, representing $18.75 \%$ of enterprises. A total of 30 questions were answered by 50 companies, or $12.5 \%$ of the companies contacted.

Among the surveyed companies, $56 \%$ have up to 100 employees, $15 \%$ have between 101 and 500, and 24\% have more than 500 employees. The sample comprises $55 \%$ of companies operating as FFs without issuing their BL. The remaining $45 \%$ of companies identify themselves as NVOCC companies, and they issue their house BL. According to the annual business volume, $29 \%$ of companies have an annual turnover of up to 1,000 TEU, 25\% have ship 10,000 TEU, while $45 \%$ control above 10,000 TEU. In terms of container market traffic, $72 \%$ of companies are mainly those operating between Asia and Europe and in the opposite direction, and 8\% each operate mainly in the axis Asia-North America and EuropeNorth America. The majority of South American and Asian businesses and vice versa are significant for $7 \%$ of the surveyed companies, while $3 \%$ is represented by companies that predominantly operate between South America and Europe and between Africa and Europe.

\section{Results}

According to the data collected, $8 \%$ of companies no longer have the option of negotiating named account rates (NAC), and $24 \%$ have an option with just one or two CLs, while just $13 \%$ of respondents have never negotiated NAC terms. The remaining $56 \%$ of surveyed companies have the possibility of negotiating NAC terms, which are valid for a month or longer.

As many as $82 \%$ of companies have already encountered a new way of spot booking and dynamic adjustment of ocean rates, but $43 \%$ do not use a new way of working. Besides, $19 \%$ of respondents have not yet encountered a changed booking method. Of the companies, $21 \%$ think that this type of work is more suitable only for importing containers, $32 \%$ only for export, and $46 \%$ think that this type of work is suitable for both the organization of import and export of containers. Surprisingly enough, $74 \%$ of companies want to do business with CLs in the traditional way (longer fixed rates), and only $26 \%$ of companies prefer CLs that are introducing a new way of booking and dynamically setting ocean rates.

The survey highlights that slightly over half of companies do not approve dynamic adaption of ocean rates and additional charges for moving the booking or cancellation (56\%), while almost one-third of respondents approve the new way of working. For the remaining $11 \%$ of companies, the new way of work is not relevant for their actual business. Moreover, these companies do not show the need for additional knowledge of the new way of working. A relatively high proportion of companies $(51 \%)$ are unaware of spot booking methodology and how shipping rates are changing. Only 39\% are aware of the new approach. Somewhat higher is the proportion of companies familiar with and evaluating work as a user-friendly tool when working on a CL's web-based booking platform. However, as many as $40 \%$ of companies believe working through shipping portals for space reservations for containers is not a user-friendly environment to simplify FFs' operational work. 
The study also exposes companies' need for a more transparent and extensive presentation of the methodology for setting dynamic ocean rates. Namely, $49 \%$ of companies believe that CLs should have a more transparent explanation of pre-booking pricing and, eventually, for higher rates applied a few days before a ship's arrival. The need for a more detailed explanation primarily lies in the possibility to properly inform cargo owners and to better anticipate their own business risk. However, the remaining 51\% of companies do not consider it necessary that CLs do so, or they can do it later as the new way of working becomes more widespread.

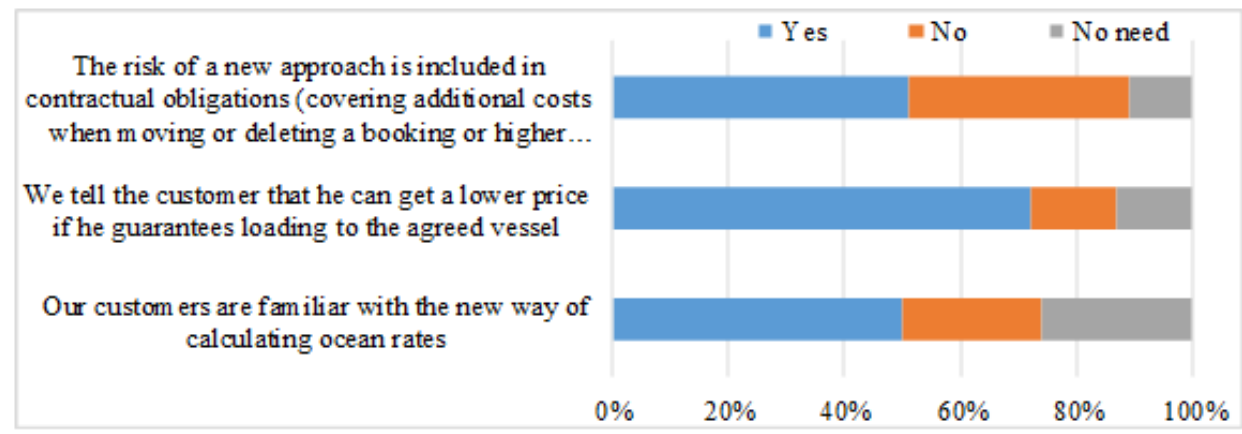

Fig. 2 Share of freight forwarder's approach in notifying cargo owners about new CL price and booking policy

FFs and NVOCCs consider that they are exposed to a higher risk of organizing overseas supply chains with a new way of working. Thus, most companies (53\%) do not take the risk or make a booking with the CL if they do not have a transport order in their hands, as they are aware of the additional cost of moving the booking or its cancellation. The remaining $43 \%$ of companies do this for just a few TEU weekly, while $2 \%$ of companies (offices) do this for 25 TEU per week or even 50 TEU per week. A total of $38 \%$ of companies consider the dynamic change in ocean rates as a risk to their own business. A relatively low percentage $(17 \%)$ believe that they do not pose a risk, while $45 \%$ are undetermined due to the short period of operation with the new approach in container shipping. As a result, most FFs and NVOCCs inform cargo owners about changes in the booking (50\%) and that they can obtain a lower price with booking pre-announcement ( $72 \%$ ). Moreover, $51 \%$ of surveyed companies include these risks in mutual contractual obligations (Fig. 2).

Table 1 Freight forwarder and NVOCC opinions on the cost of moving or canceling the booking

\begin{tabular}{|l|c|c|c|c|c|c|}
\hline & \multicolumn{7}{|c|}{ Answers } \\
\hline & $\begin{array}{c}\text { Up to 10 } \\
\text { USD/TEU }\end{array}$ & $\begin{array}{c}\text { Up to 20 } \\
\text { USD/TEU }\end{array}$ & $\begin{array}{c}\text { Up to 50 } \\
\text { USD/TEU }\end{array}$ & $\begin{array}{c}\text { Up to 100 } \\
\text { USD/TEU }\end{array}$ & $\begin{array}{c}\text { Up to 200 } \\
\text { USD/TEU }\end{array}$ & Total \\
\hline $\begin{array}{l}\text { Booking postponement } \\
\text { on next vessel }\end{array}$ & $44 \%$ & $30 \%$ & $26 \%$ & $0 \%$ & $0 \%$ & $100 \%$ \\
\hline Booking cancelation & $41 \%$ & $35 \%$ & $24 \%$ & $0 \%$ & $0 \%$ & $100 \%$ \\
\hline
\end{tabular}

When asked what cost in USD per TEU is still acceptable for FFs and NVOCCs when moving a booking to the next ship or canceling it, the companies have expressed their willingness to cover costs up to USD 50 per TEU (Table 1). Most believe that the cost is acceptable for USD 10 per TEU, while 30\% think the cost of booking postponement is acceptable up to USD 20 per TEU, and 35\% agree on the same amount for booking cancellation. Just $26 \%$ of companies believe that the cost of up to USD 50 per TEU is suitable for postponing the booking, and $24 \%$ of companies think that such an amount is also suitable for booking cancellation. 
FFs are predominantly not open to accepting a higher ocean rate based on freight allkind rate (FAK) for last-minute reservations, which could be 2 to 3 days before the ship's arrival $(61 \%)$. Of the remaining 39\% of companies approving the described approach, $43 \%$ accept a $5 \%$ increase, $29 \%$ of companies accept up to a $10 \%$ increase, and $5 \%$ agree with a $15 \%$ increase on the FAK rate. Some companies agree on a $20 \%$ increase $(10 \%)$ and even more than a $25 \%$ increase over the FAK rate $(14 \%)$.

For the most part, FFs and NVOCCs feel that their customers are not ready to make space reservations earlier than 3 to 4 weeks before the ship arrives in port. According to FF's opinion (43\%), clients' interest in booking a reservation at which they can obtain a lower ocean rate than the FAK tariff is only three weeks before E.T.A. (Fig. 3). However, on average, as many as one-third of FFs do not yet have this information from customers, highlighting the need for additional operational coordination.

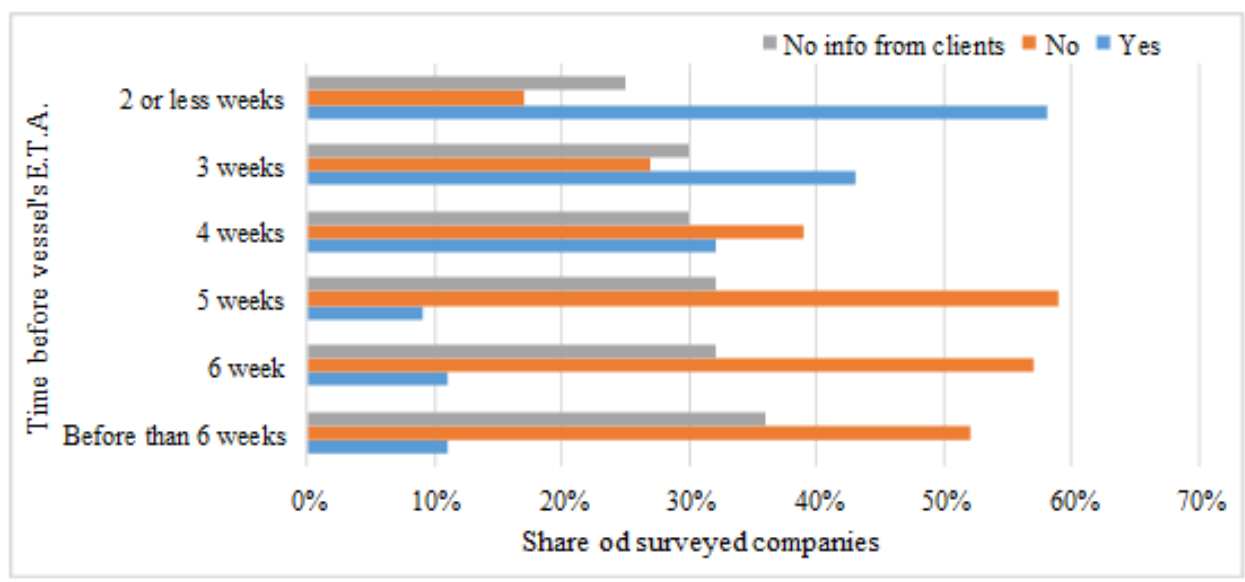

Fig. 3 Time frames for placing a booking by COs

When asked if companies feel that a new way of setting ocean rates increases or decreases the role of the FFs in the intermodal chains (or will have an impact in the future), $53 \%$ think that it is reducing. Of these, as many as $22 \%$ believe that the new way of working reduces FF's role importantly. On the other hand, 24\% consider that changes do not impact their work, while $20 \%$ believe that the changes give a more important role to the FF in the organization of maritime and intermodal transport. However, only $4 \%$ believe that the new way of working increases their role greatly.

Companies are quite restrained in predicting that a different way of working with container bookings will strengthen their commercial activity, with 35\% estimating that they will be unaffected and as much as $42 \%$ of companies have difficulties assessing at present whether their commercial approach to cargo owners will change. Only $24 \%$ of surveyed companies believe that they will strengthen their commercial operations with a new way of working.

Table 2. Assessment of changes in freight forwarders and NVOCCs work

\begin{tabular}{|l|c|c|c|c|}
\hline & \multicolumn{3}{|c|}{ Answers } \\
\hline Operational activities & Yes & No & $\begin{array}{c}\text { Hardly to } \\
\text { evaluate }\end{array}$ & Total \\
\hline Increases administrative work & $56 \%$ & $26 \%$ & $18 \%$ & $100 \%$ \\
\hline Increases communication with the customer & $69 \%$ & $16 \%$ & $14 \%$ & $100 \%$ \\
\hline Increases communication with the carrier & $55 \%$ & $39 \%$ & $6 \%$ & $100 \%$ \\
\hline $\begin{array}{l}\text { Increases the possibility of errors in the calculation } \\
\text { of ocean rates to the customer }\end{array}$ & $71 \%$ & $14 \%$ & $16 \%$ & $100 \%$ \\
\hline
\end{tabular}


Companies also estimate the impact on their business very similarly (Table 2), as between $55 \%$ and $71 \%$ believe that the new way of booking and setting ocean rates increase their administrative work, communication with the customer, communication with the shipping company, and the possibility of a higher level of errors in the calculation of shipping costs to customers. On the other hand, companies have a shared view of achieving the logistical margin due to a changed way of working. A reduction of the logistical margin is expected by $36 \%$ of the companies surveyed, while $28 \%$ believe the opposite. They believe that their logistical margin will increase with a changed way of working. However, a fairly high percentage of respondents (36\%) think that the new way of working will not affect their margin.

FFs and NVOCCs are open to accepting visits from CLs or their agents to show them the benefits and ways of a new approach to book space on container ships, with $61 \%$ of companies ready for this type of meeting. Of these, $25 \%$ are ready to devote up to 15 minutes to the meeting, $50 \%$ to 30 minutes, $21 \%$ to one hour, and $4 \%$ more than one hour. However, most companies are reluctant to pay membership fees to join a single e-booking platform (single window) and to compare and use dynamically changed ocean rates, which could otherwise make it easier for them to operate as they make bookings on separate shipping systems and web-based access points presently. Only $18 \%$ of companies would be willing to pay up to USD 200 per month for such an e-platform.

\section{Discussion and implications}

The changed way of working in the shipping container industry will significantly impact the future work of FFs and NVOCC operators. Undoubtedly, CL needs to change their way of working to avoid overbooking and container rolling from booked ships to next sailings. At the same time, they have to pay attention to the occupancy of the cargo space, which they regulate by charging postponement of bookings on the next ship or even cancel them. The survey points out that FFs are not in favor of doing so (56\% of companies) and, above all, not to a higher rate for moving or canceling bookings (Fig. 4). Moreover, in figure 4, important opinions of FFs and NVOCCs are exposed that can be useful in modelling new approaches to implement new booking and pricing policies by CLs.

The analysis exposes that almost three-quarters of companies prefer to work with a CL traditionally offering ocean rates by fixing price and validity. It takes time to make changes, but the whole industry will adjust when most CLs adopt the same or similar business model. A similar step-by-step modification happened in the air transport industry.

The study also highlights that half of analysed FFs and NVOCC operators see that CLs are pushing them out of business with the increasingly digitalized way of working along intermodal chains (Fig. 4). Despite this, they estimate that operational tasks are increasing with the new way of working (opinion of $69 \%$ of companies), but at the same time, they are struggling for their position and the level of logistical margin. More than half of the surveyed companies point out that they successfully pass a higher business risk level to the $\mathrm{CO}$ or their customers. The latter is also defined in their mutual contractual obligations. This is especially important given the fact that COs are averse to early booking. They prefer to make reservations two to three weeks before the ship's arrival, which does not suit the CL, as this increases the risk of lowering the vessel's cargo space utilization. As shown in figure 4, the analysis also points out that FFs and NVOCCs are not keen on the possibility that ocean rates might rise in the last week before the vessel's arrival, as $61 \%$ of surveyed companies expressed such a negative opinion. 


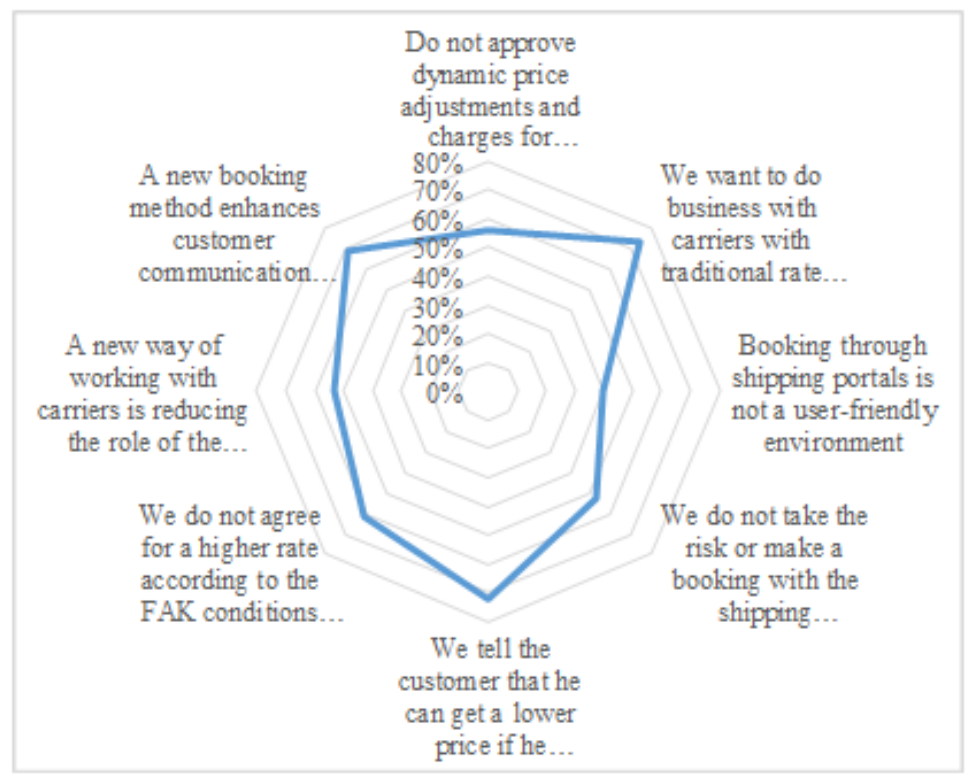

Fig. 4 Obtained key opinions of FF and NVOCC operators for developing strategic customization approach

In line with the study results, a three-step approach is proposed to make the new approach in booking and accepting the new formulation of ocean rates more efficient (Fig. 5). By applying proposed measures, the interest of FFs in the new way of working can be increased and reduce their perception of exposure to the risks posed by the new approach. As a first step, CLs should define a clear methodology for setting the ocean rate to increase the confidence level of FFs and NVOCCs. There is also a need for a transparent and valid ocean rate policy so that FFs and NVOCC operators can present it to COs toward convincing them to make pre-booking as early as possible.

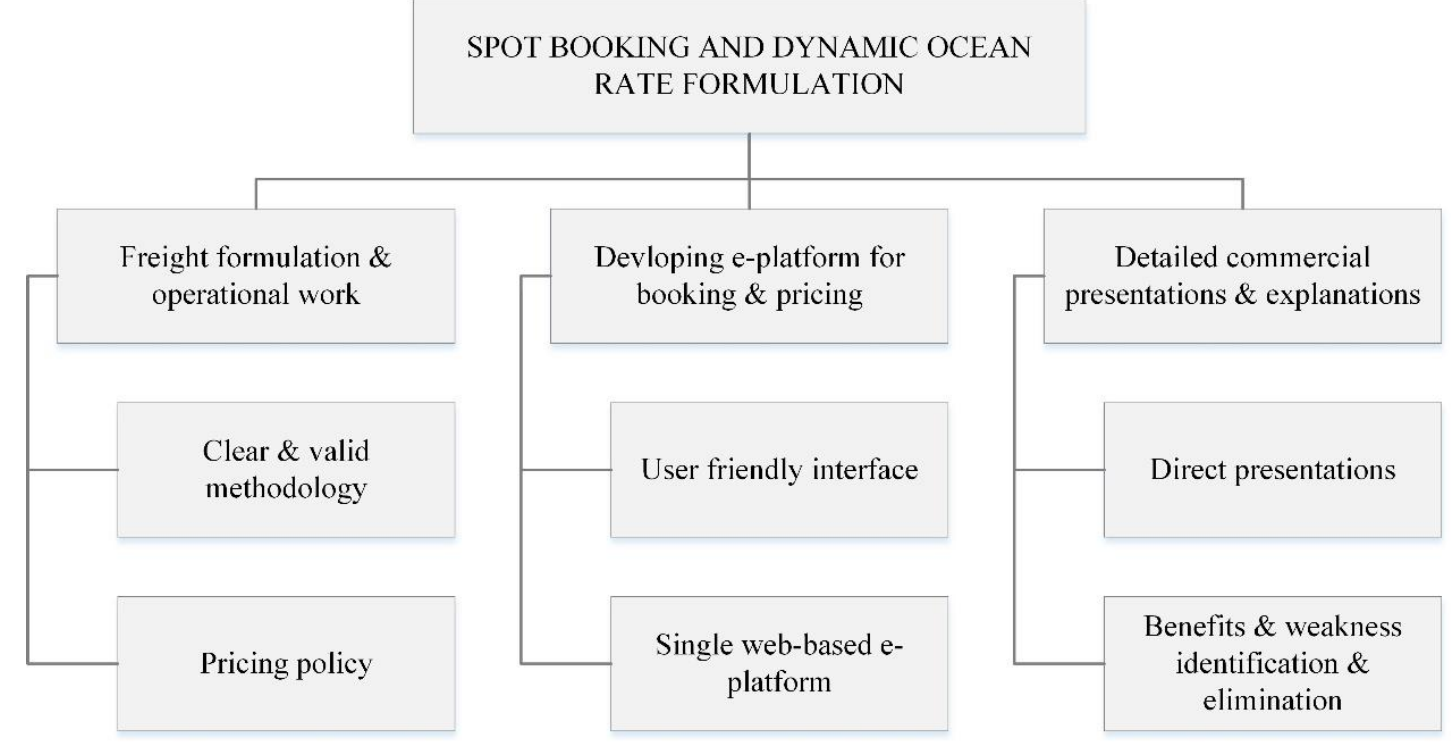

Fig. 5 Approaches to encourage freight forwarders and NVOCCs to use a new way of working

The second step is more technically oriented as it is related to the method of the booking process. FFs perceive the current mode of booking via the CLs' systems as less user friendly. CLs can improve the interfaces for obtaining booking information and may approach a unified e-platform solution through which FFs with standardized data entry would send booking information to the selected CL, which has already been done to some extent with the INTTRA Ocean Trade Platform [28]. However, such a system would be upgraded by 
integrating the dynamic modification of the selected CL's ocean rates. Such a platform or single window could contain the current cost of maritime transport by different CLs, which would allow FFs spot-selection of the CL. The survey shows that FFs are reluctant to pay extra money for this kind of e-commerce. However, the third step is oriented towards the CL to speed up their commercial activities concerning exposing the benefits of a new way of working to the FFs and the positive benefits for the entire maritime industry. According to the survey, most companies confirm their readiness for such meetings.

\section{Conclusion}

The maritime industry must adapt to the new guidelines and requirements of the global economy. Adaptations include shortening supply chains, which today are partly extended due to overbooking and rolling of containers. CLs are making changes that influence FFs and NVOCCs the traditional way of working in maritime logistics. This is evidenced by the results of a survey between FFs and NVOCCs globally. The first thesis (H1) that FFs have concerns about a new spot booking method and a dynamic way of setting ocean rates can be partially confirmed. Just over half of the companies are reluctant to the new approach from CLs, and also half of the companies see problems with multi-week pre-booking as they do not receive a booking confirmation from cargo owners. Moreover, almost three-quarters of FFs prefer to manage ocean rates by receiving traditional offers with fixed price and validity, and only one-third of companies expect a reduction of their logistical margin due to the new booking and pricing method.

The survey points out also that half of the companies feel that a new way of setting ocean rates reduces their role in the intermodal chains and the same share of companies see that CLs are pushing them out of business with the increasingly digitalized way of working along intermodal chains. Consequently, the result just partially confirms the second thesis (H2) that FFs feel threatened by CLs because they are gradually pushing them from the organization of intermodal transport chains. Anyhow, the results highlight the need to bring a new way of working closer to needs and expectations. CLs' initiatives are certainly needed to provide a more transparent booking process, but they need to be as flexible as possible with the expectations of FFs, NVOCCs, and CO. The survey highlights key areas where stakeholders are expected to engage CLs actively. The presented three-step approach covers specific areas that make FFs and NVOCCs operational and commercial work easier and lower business risk levels. In this manner, CLs would more effectively implement a modified mode of operation that will surely, to some extent, affect stakeholders' business approaches. The survey highlights the importance of a transparent and valid pricing policy that is clear to FFs and cargo owners, thereby reducing the recorded levels of fear and business risk presently displayed by FFs and NVOCCs. Due to the importance of the overbooking process and the dynamic ocean rate formation on the ship's cargo space utilization, the purpose is to further deepen the opinion of stakeholders in intermodal transport by extending the survey sample to COs, maritime agents, and CLs, which should be carried out through future research. An upgraded approach to the spot booking implementation would be possible to elaborate by obtaining further data and collecting suggestions.

\section{REFERENCES}

[1] Blanco, B., Pérez-Labajos, C. and García, E. (2007). Behaviour of sea freight traffic model, Journal of Maritime Research, 4(3), pp. 87-104.

[2] Notteboom, T. and Cariou, P. (2013). Slow steaming in container liner shipping: is there any impact on fuel surcharge practices, The International Journal of Logistics Management, 24(1), pp. 73-86.

https://doi.org/10.1108/IJLM-05-2013-0055 
[3] Das, S.S. (2011). To partner or to acquire? A longitudinal study of alliances in the shipping industry, Maritime Policy and Management, 38(2), pp. 111-128. https://doi.org/10.1080/03088839.2011.556677

[4] Slack, B., Comtois, C. and McCalla, R. (2002). Strategic alliances in the container shipping industry: a global perspective, Maritime Policy and Management, 29(1), pp. 65-76. https://doi.org/10.1080/03088830110063694

[5] Yap, W. and Zahraei, S. (2018). Liner shipping alliances and their impact on shipping connectivity in Southeast Asia, Maritime Business Review, 3(3), pp. 243-255. https://doi.org/10.1108/MABR-05-2018$\underline{0018}$

[6] Chou, M., Song, M. and Teo, C.P. (2003). Inventory-Routing Problem in Sea Freight: Direct versus Transshipment Model, Report within the Sea Cargo Logistic Project Singapore: National University of Singapore.

[7] Jurišić, P., Parunov, J. and Garbatov, Y. (2017). Aging effects on ship structural integrity, Brodogradnja - Shipbuilding, 68(2), pp. 15-28. https://doi.org/10.21278/brod68202

[8] Akdemir, B. and Beskese, A. (2019). A decision-support tool for demolition sale of a vessel, Brodogradnja - Shipbuilding, 70(3), pp. 153-173. https://doi.org/10.21278/brod70309

[9] Stopford, M. (2009). Maritime Economics, 3rd ed., Routledge, New York, USA. https://doi.org/10.4324/9780203891742

[10] Drewry Maritime Research (2018). Container Market Outlook \& Freight Rate Trend, Drewry Maritime Research, London, UK.

[11] UNCTAD (2018). Review of maritime transport, United Nations Publications, New York, USA.

[12] Nielsen, P., Jiang, L., Rytter, N.G.M. and Chen, G. (2014). An investigation of forecast horizon and observation fit's influence on an econometric rate forecast model in the liner shipping industry, Maritime Policy and Management, 41(7), pp. 667-682. https://doi.org/10.1080/03088839.2014.960499

[13] Munim, Z.H. and Schramm, H.J. (2017). Forecasting container shipping freight rates for the Far East Northern Europe trade lane, Maritime Economics \& Logistics, 19(1), pp. 106-125. https://doi.org/10.1057/s41278-016-0051-7

[14] Steenken D., Winter T. and Zimmermann U.T. (2001). Stowage and Transport Optimization in Ship Planning. in: Grötschel M. at al. (Eds.), On-line Optimization of Large Scale Systems, Springer, Berlin, Germany. https://doi.org/10.1007/978-3-662-04331-8_35

[15] Ting, S.C. and Tzeng, G.H. (2004). An optimal containership slot allocation for liner shipping revenue management, Maritime Policy \& Management, 31(3), pp. 199-211. https://doi.org/10.1080/0308883032000209553

[16] Wang, X. and Fung, R.Y.K. (2014). An option-based hedging mechanism for managing the risk of overbooking in parallel airline alliances, Transport Research Part E: Logistics and Transportation Review, 70(1), pp. 146-162. https://doi.org/10.1016/j.tre.2014.06.014

[17] Wang, T., Xing, Z., Hu, H. and Quc, X. (2019). Overbooking and delivery-delay-allowed strategies for container slot allocation, Transportation Research Part E, 122, pp. 433-447. https://doi.org/10.1016/j.tre.2018.12.019

[18] Chew, E.P., Huang, H.C., Johnson, E.L., Nemhauser, G. L., Sokol, J. S. and Leong, C. H. (2006). Shortterm booking of air cargo space, European Journal of Operational Research, 174(3), pp. 1979-1990. https://doi.org/10.1016/j.ejor.2005.05.011

[19] Vinod, B. and Narayan, C. P. (2008). On optimising cargo rates to improve the bottom line, Journal of Revenue and Pricing Management, 7(4), pp. 315-325. https://doi.org/10.1057/rpm.2008.38

[20] Maersk (2019). Maersk introduces Maersk Spot, a new fully on-line product that simplifies the buying process for customers'. Available at: https://www.maersk.com/news/articles/2019/06/25/maerskintroduces-maersk-spot

[21] Zurheide, S. and Fischer, K. (2015). Revenue management methods for the liner shipping industry, Flexible Services and Manufacturing Journal, 27(2-3), pp. 200-223. https://doi.org/10.1007/s10696-0149192-0

[22] Oblak, R., Jugović, A. and Perić Hadžić, A. (2016). Defining freight rates as a contribution to the successful operation of container shipping companies, Management: Journal of Contemporary Management Issues, 21(2), pp. 145-163.

[23] Zhao, Y.C. (2015). Sea freight cost reduction by long term contract, Journal of Supply Chain Management Research and Practice, 9(1), pp. 50-62. 
[24] Charles, J. (2020). Dynamic container pricing gives carriers repositioning edge, The Journal of Commerce, Available at: https://www.joc.com/international-logistics/dynamic-container-pricing-givescarriers-repositioning-edge_20200327.html.

[25] van den Berg, R. and de Langen, P. (2015). Assessing the intermodal value proposition of shipping lines: Attitudes of shippers and forwarders, Maritime Economics and Logistics, 17(1), pp. 32-51. https://doi.org/10.1057/mel.2014.11

[26] Kannan, V., Bose, S.K. and Kannan, N.G. (2011). An evaluation of ocean container carrier selection criteria: An Indian shipper's perspective, Management Research Review, 34(7), pp. 754-772. https://doi.org/10.1108/01409171111146661

[27] Notteboom, T. and Merckx, F. (2006). Freight Integration in Liner Shipping: A Strategy Serving Global Production Networks, Growth and Change, 37(4), pp. 550-569. https://doi.org/10.1111/j.14682257.2006.00340.X

[28] Lun, Y.H.V. and Quaddus, M.A. (2011). Firm size and performance: A study on the use of electronic commerce by container transport operators in Hong Kong, Expert Systems with Applications, 38(6), pp. 7227-7234. https://doi.org/10.1016/j.eswa.2010.12.029

\section{Appendix}

\section{Survey structure and content}

\begin{tabular}{|c|c|}
\hline No. & Question \\
\hline \multicolumn{2}{|c|}{$1^{\text {st }}$ section } \\
\hline 1. & The country where you perform freight forwarding service (location of your office) \\
\hline 2. & The number of employees in your company on a global scale: \\
\hline 3. & How do you perform freight forwarder shipping business? \\
\hline 4. & $\begin{array}{l}\text { The annual volume of TEU on the level of the whole company: up to 1,000 TEU, up to 10,000 TEU or over 10,000 } \\
\text { TEU. }\end{array}$ \\
\hline 5. & The majority of maritime transport operations related to markets: (Asia-Europe, Asia-N. America etc.). \\
\hline \multicolumn{2}{|r|}{$2^{\text {nd }}$ section } \\
\hline 6. & $\begin{array}{l}\text { Do you still have the option to negotiate ocean rates with important container shipping companies based on your } \\
\text { Named Account Pricing }(N A C) \text { valid for a month or longer? }\end{array}$ \\
\hline 7. & $\begin{array}{l}\text { Do you approve the new way of forming ocean rates that are formed when bookings are placed for a particular ship } \\
\text { and are dynamically changing depending on the available space on the ship? }(Y / N)\end{array}$ \\
\hline 8. & $\begin{array}{l}\text { In your work, do you encounter a new way of forming an ocean freight that is dynamically formed when the booking is } \\
\text { placed with a Container Liner? (Y/N) }\end{array}$ \\
\hline 9. & Is the modified method more suitable for booking a container: import, export, both. \\
\hline \multicolumn{2}{|r|}{$3^{\text {rd }}$ section } \\
\hline 10. & $\begin{array}{l}\text { Is the dynamic formation of ocean freight according to the ship's space more than once a week understandable for you } \\
\text { and your client? }(Y / N)\end{array}$ \\
\hline 11. & $\begin{array}{l}\text { Is the way of working or using the e-platform for a dynamic change of ocean rate and booking a well-designed and } \\
\text { user-friendly tool? (Y/N/do not know how it works) }\end{array}$ \\
\hline 12. & $\begin{array}{l}\text { Should shipping companies better explain the pricing methodology (algorithms that alter the ocean rate behind their } \\
\text { program)? (Y/N/perhaps in the future) }\end{array}$ \\
\hline 13. & Why would the explanation be needed? \\
\hline 14. & $\begin{array}{l}\text { Do you take the risk of the potential shipping costs for booking postponement/booking cancelation, even if you do not } \\
\text { have orders from your customers, but you still make a booking with a carrier in order to obtain a lower ocean rate? }\end{array}$ \\
\hline 15. & $\begin{array}{l}\text { In our work, it is considered that: } \\
\text { - our customers are informed about the new way of formulating shipping fares: Y/N/no need. } \\
\text { - we tell the customer that he can get a lower price if he guarantees the loading on the agreed ship: Y/N/no need. } \\
\text { - we include the risk of new fare formation in mutual contractual obligations (covering additional costs when moving } \\
\text { or deleting the booking; higher ocean rates): Y/N/no need. }\end{array}$ \\
\hline 15. & What cost in USD/TEU is acceptable to you for booking postponement for the next vessel and for booking cancelation. \\
\hline 16. & $\begin{array}{l}\text { Would you accept a higher fare price for a last-minute booking (2 days before the ship) on FAK (Basic) ocean rate? } \\
(Y / N)\end{array}$ \\
\hline 17. & Price could be higher by: $5 \%, 12 \%, 15 \%, 20 \%$ over $25 \%$ on FAK rate. \\
\hline 18. & $\begin{array}{l}\text { Do you feel that a new way of shaping the ocean rate increases or decreases the role of a freight forwarder in } \\
\text { intermodal chains (or will it impact the future)? }\end{array}$ \\
\hline 19. & $\begin{array}{l}\text { Will a new way of defining ocean freight at the booking strengthen your commercial activity in acquiring new } \\
\text { customers? (Y/N/can't evaluate) }\end{array}$ \\
\hline \multicolumn{2}{|c|}{$4^{\text {th }}$ section } \\
\hline 20. & $\begin{array}{l}\text { Do you consider a new way of defining ocean rates when making a booking to a shipping company as a commercial } \\
\text { risk to your business? (Y/N/we can't evaluate) }\end{array}$ \\
\hline
\end{tabular}




\begin{tabular}{|l|l|}
\hline 21. & $\begin{array}{l}\text { Do you see that by the new way of working, or can you predict that in the new way of working, you will face: increased } \\
\text { administrative work, enhanced communication with the customer, enhanced communication with the carrier/agent or } \\
\text { the increased possibility of errors in the calculation of ocean freight to the customer. (Y/N/we hardly evaluate it } \\
\text { presently) }\end{array}$ \\
\hline 22. & $\begin{array}{l}\text { Does the new way of working influence the level of your logistics margin? Lowering the margin, increasing the } \\
\text { margin, or it has no influence, the margin remains the same. }\end{array}$ \\
\hline 23. & $\begin{array}{l}\text { Do you prefer to book with a carrier/agent introducing a new pricing method, or do you prefer carriers with a } \\
\text { traditional pricing policy (pricing just with FAK rates)? A new way to dynamically change the ocean rate according to } \\
\text { booking date or traditional way, where the ocean rate is fixed for a fixed time. }\end{array}$ \\
\hline $\mathbf{5}^{\text {th }}$ section \\
\hline 24. & $\begin{array}{l}\text { Would it be possible for a shipping representative to present a new way of formulating their ocean freight personally? } \\
\text { (Y/N) }\end{array}$ \\
\hline 25. & For the presentation, we would take: $15,30,60$, or over 60 minutes. \\
\hline 27. & Are customers interested in advance booking (to get lower ocean rates): 6,5,4,3,2 weeks before loading on the vessel? \\
\hline 28. & $\begin{array}{l}\text { Are you ready to pay a subscription fee for accessing a single e-platform in the future, where all shipping companies } \\
\text { would publish dynamically adjusted ocean rates (in a single location) concerning each ship's space, and could the } \\
\text { ocean rate increase and decrease? (Y/N/we have not yet considered this possibility) }\end{array}$ \\
\hline 29. & An acceptable membership fee would be: up to 200/500/1,000/ over 1,000 USD/month. \\
\hline
\end{tabular}

Submitted: $\quad 02.07 .2020$

Accepted: $\quad 20.11 .2020$.
Bojan Beškovnik, Ph.D., Bojan.beskovnik@fpp.uni-lj.si Faculty of Maritime Studies and Transport, University of Ljubljana, Pot pomorščakov 4, 6320 Portorož, Slovenija 